\title{
What have we learned from in vitro intravascular ultrasound?
}

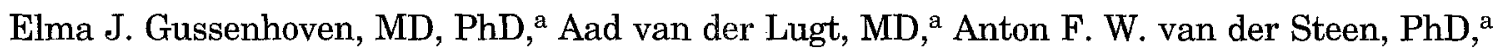 \\ and Kees M. Ligtvoet, $\mathrm{MSc}^{\mathrm{b}}$ Rotterdam and Utrecht, The Netherlands
}

The clinical use of intravascular ultrasound provides additional diagnostic information to assist with catheter-based interventions. To understand more fully the information provided by intravascular ultrasound, numerous in vitro validation studies have been performed to compare the ultrasound data with their histologic counterparts.

We present an overview of the intravascular ultrasound studies performed in vitro, discuss the differences between in vitro and in vivo application of intravascular ultrasound, and describe some current in vitro research on intravascular ultrasound aimed at supplementing diagnostic information.

\section{VISUALIZATION OF THE ARTERIAL WALL}

The first qualitative in vitro study performed with samples of human iliac and femoral arteries was reported in 1988 by Meyer et al. ${ }^{1}$ Small lengths $(\cong 1 \mathrm{~cm}$ ) of arteries were fixed into glass test tubes, which were then filled with saline for imaging with a 20 $\mathrm{MHz}$ transducer. On the ultrasound image of a normal artery the intima was echogenic; the media was hypoechoic; and the adventitia was hyperechoic. Compared with connective tissue, the muscular media appeared hypoechoic on ultrasound scans, probably because of a relative lack of collagen. In the same year, Pandian et al. ${ }^{2}$ examined the aorta, iliac, carotid, and coronary arteries from animals. A small wedge of arterial wall was resected in the vessel circumference for ultrasound anatomic orientation. The ultrasound images $(20 \mathrm{MHz})$ portrayed a bright homogeneous arterial wall without distinction among intima, media, and adventitia.

From the aThoraxcenter, University Hospital Rotterdam-Dijkzigt and ${ }^{\text {b the }}$ Academic Hospital Utrecht, the Netherlands Heart Foundation, and the Interuniversity Cardiology Institute.

Received for publication December 27, 1995; accepted February 1, 1996.

Reprint requests: Elma J. Gussenhoven, MD, Erasmus University Rotterdam, Department of Echocardiology (Ee 2312), P.O. Box 1738, 3000 DR, Rotterdam, The Netherlands

Am Heart J 1996;132:702-10.

Copyright (C 1996 by Mosby-Year Book, Inc.

$0002-8703 / 96 / \$ 5.00+0 \quad \mathbf{4 / 1 / 7 3 6 7 7}$
Subsequently, in 1989 , using a $40 \mathrm{MHz}$ ultrasound system, we studied $1 \mathrm{~cm}$-long human carotid and iliac arteries embedded in a $1.2 \%$ solution of agaragar $^{3}$; it was observed that intravascular ultrasound has the ability to differentiate elastic (carotid) from muscular (iliac) type of arteries. The ultrasound appearance corresponded to the histologic differences in the media. The media of a muscular artery composed of smooth muscle cells was practically devoid of elastin fibers, whereas the media of an elastic artery consisted mainly of densely packed, concentrically arranged elastin fibers amid smooth-muscle cells. On ultrasound a muscular artery was identified by the hypoechoic media; both intima and adventitia were clearly defined, showing bright echoes (Fig. 1). An elastic artery was identified by a media that was as bright as its surrounding tissues. We assumed that the presence of elastin fibers regularly arranged in the media was responsible for a significant amount of acoustic backscatter, with a power level comparable with that from the intima and adventitia. In subsequent studies, we established that aorta, carotid, subclavian, and internal thoracic arteries appeared as elastic arteries, whereas the coronary, brachial, mesenteric, splenic, renal, and iliofemoral arteries were muscular in nature ${ }^{4,5}$ (Fig. 2). Others have subsequently confirmed that elastic arteries have a homogeneous arterial wall, whereas muscular arteries have a characteristic three-layered arterial wall. ${ }^{6-11}$

Differences in the relative concentration and organization of collagen and elastin provided a consistent explanation for the differences in scatter observed within the arterial wall with $45 \mathrm{MHz}$ intravascular ultrasound imaging. ${ }^{11}$ Noteworthy is that an elastic artery may gradually merge into a muscular artery; thus in coronary and iliac arteries, which are predominantly muscular, elastin fibers may be present in the media, particularly near the origin. ${ }^{4}$ However, in muscular arteries the medial layer may not always be visible on ultrasound. Thinning of the arterial media is a well-known process of atheroscle- 

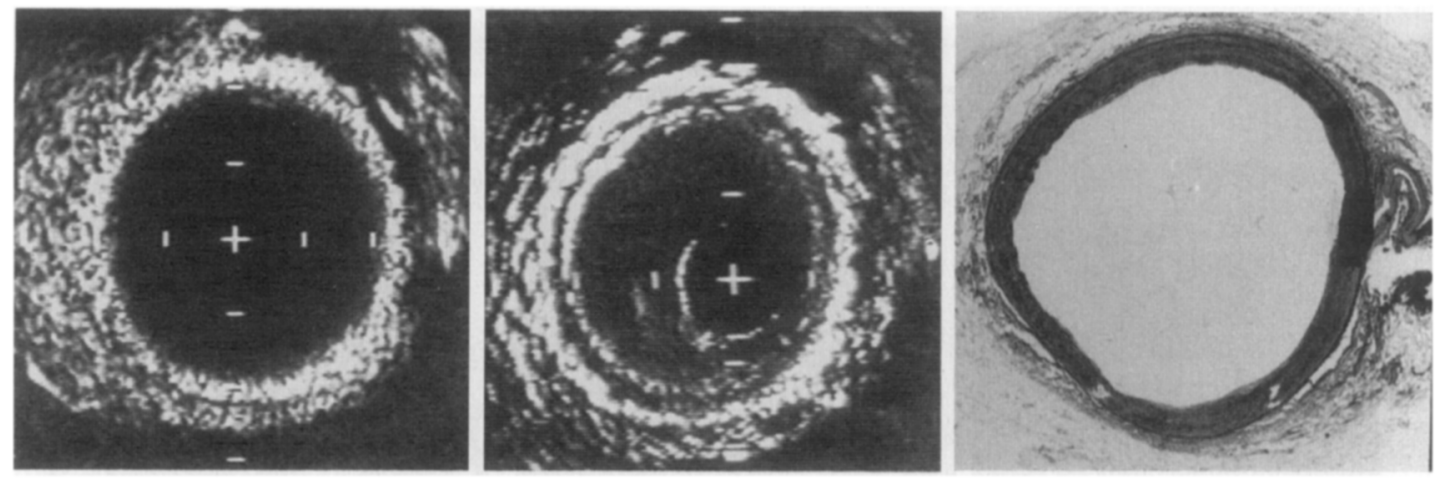

Fig. 1. Intravascular ultrasound cross-sections (left and middle) obtained at same level within pressureperfused $(100 \mathrm{~mm} \mathrm{Hg}$ ) coronary artery with two different ultrasound catheters operating at $30 \mathrm{MHz}$. Images demonstrate how limited axial resolution can influence image quality. Left, Inability to visualize arterial media resulted from electronic matching problem. Middle, Catheter with optimal pulse identified media of $0.2 \mathrm{~mm}$. Right, Corresponding histologic section evidenced muscular nature of artery. Calibration: $1 \mathrm{~mm}$. (From Gussenhoven et al. In Roelandt et al., eds. Intravascular ultrasound. Dordrecht: Kluwer Academic, 1993:45-62. Reprinted by permission of Kluwer Academic Publishers.)

rosis and affects visualization of the media on ultrasound images. ${ }^{12}$ In addition, the echolucent layer of the media may be only barely discernible when medial collagen content is increased ${ }^{13,14}$ (Fig. 3). Borst et al. ${ }^{15}$ reported on the absence of a visible hypoechoic media in relatively normal coronary arteries: they questioned whether the presence or absence of an echolucent zone was related to age. Fitzgerald et al. ${ }^{16}$ observed that the degree of intimal thickening was indeed related to age and that intimal thickening of $\geq 0.18 \mathrm{~mm}$ facilitated identification of the hypoechoic media in normal coronary arteries on ultrasound examination.

Thus visibility of the hypoechoic media is related to media thickness and the limits of the axial resolution of the intravascular ultrasound system used. Media thickness has been determined to be $0.2 \mathrm{~mm}$ in normal coronary arteries and $0.8 \mathrm{~mm}$ in normal iliofemoral arteries. ${ }^{17}$ With higher ultrasound frequency, and thus improved resolution, better identification of the tunica media, particularly in the small coronary arteries, is possible. Visualization of the tunica media also may depend on near-field resolution and electronic matching of the ultrasound catheter used. This aspect was studied in vitro with two different ultrasound catheters (Du-MED, Rotterdam, The Netherlands) in the same coronary segment; both catheters operated at $30 \mathrm{MHz}$. When a catheter with a prolonged pulse (i.e., limited axial resolution) was used, the media was indistinguishable from its surroundings because of an electronic matching problem, whereas use of a catheter with an optimal pulse allowed visualization of a distinct media of $0.2 \mathrm{~mm}$. The corresponding histologic section revealed a muscular media $0.2 \mathrm{~mm}$ thick with 0.08 $\mathrm{mm}$ intimal thickening ${ }^{17}$ (Fig. 1).

\section{CHARACTERIZATION OF ARTERIAL PLAQUE}

The first studies that assessed plaque characteristics in vitro, with $30 \mathrm{MHz}$ and $40 \mathrm{MHz}$ ultrasound transducers on coronary and peripheral arteries, demonstrated that skill in interpretation of plaque composition was learned after repeated comparison between the ultrasound image and its corresponding histologic section. ${ }^{5,7}$ Because distal coronary and peripheral arteries are predominantly muscular, the echolucent media may act as a landmark to facilitate the assessment and location (eccentric vs concentric) of plaque burden. In the presence of an atherosclerotic lesion three morphologic types of plaque were identified on ultrasound. Plaque with calcific deposits were identified by the presence of bright echoes casting echo-free shadows and may be associated with acoustic reverberation. Fibrous lesions yielded homogeneous echo reflections without echo-free shadowing, whereas extracellular lipid components appeared as a hypoechoic region inside the lesion ${ }^{7}$ (Fig. 2). Additional in vitro studies have divided the noncalcified lesion type into those yielding intermediate, soft reflections and those yielding dense, bright reflections. $5,14,18,19$

Studies on the identification of arterial thrombus, created artificially by the insertion of old human blood clots, show that this formation can be identified with moderate sensitivity and high specificity with intravascular ultrasound. ${ }^{20,21}$ The echogenic reflectance of thrombi originates mainly from red blood cells; ultrasound intensity relates linearly to the 

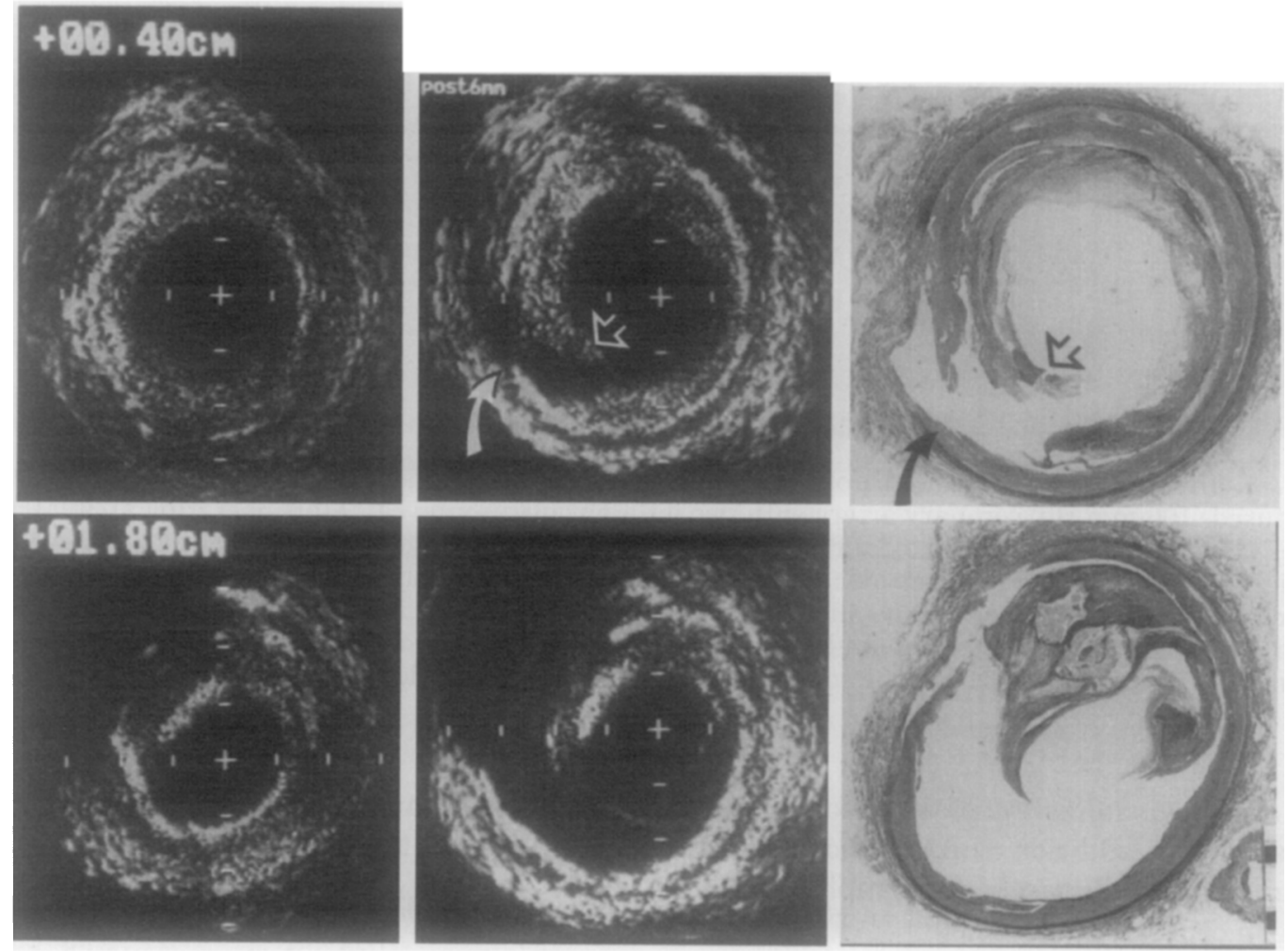

Fig. 2. Intravascular ultrasound cross-sections of pressure-perfused ( $100 \mathrm{~mm} \mathrm{Hg}$ ) superficial femoral artery obtained in vitro before (left) and after (middle) balloon angioplasty. Displacement sensing device was used to facilitate comparison of corresponding ultrasound cross-section with its histologic counterpart (right). Before balloon angioplasty, concentric soft lesion is seen at level $0.4 \mathrm{~cm}$ (top); it became dissected after intervention (open arrows). Media rupture is present on intravascular ultrasound image and on histologic section (solid arrows). At level $1.8 \mathrm{~cm}$ (bottom), eccentric hard lesion casts acoustic shadowing. Dissection and media rupture are seen after intervention. Calibration: $1 \mathrm{~mm}$.

number of cells present. ${ }^{22}$ However, distinction between thrombus and an atheromatous noncalcified lesion was not possible on ultrasound. ${ }^{20}$

In general, the sensitivity and specificity of lesion topographic features (eccentric and concentric) and lesion morphologic features (noncalcified vs calcified) with ultrasound in vitro are high, ${ }^{7,14,18,19}$ whereas for lipid, specificity is high and sensitivity low. Determinants influencing the echogenicity of a lesion, and thus accurate assessment of lipid on ultrasound, depend on the presence and magnitude of surrounding fibrous tissue, the gain setting of the system used, and the angle of incidence. ${ }^{7,23}$ Noteworthy is that "young" lipid deposits containing mainly lipid amid macrophages may appear hypoechoic on intravascular ultrasound, whereas "mature" lipid deposits amid cholesterol crystals will appear as a soft or bright structure because of the crystals (Fig. 3 ).

\section{QUANTITATIVE ASSESSMENT}

In 1988 Pandian et al. ${ }^{2}$ established an excellent correlation between intravascular ultrasound data and anatomic measurements in the estimation of vessel lumen area and diameter (Table I). The correlation for wall thickness measurements also was good. Interobserver and intraobserver variabilities in the measurements of lumen area, lumen diameter and wall thickness were negligible. Subsequent in vitro investigations have confirmed that intravascular ultrasound provides accurate measurement of lumen area, vessel area, plaque area, and wall thickness of normal and diseased arteries of varying type and size. $5,7-9,24-29$ Measurements obtained with intravascular ultrasound revealed a high correlation with measurements obtained from histologic studies (Table I). Reported interobserver and intraobserver variations were low. 7, 9, 25, 29

The majority of in vitro studies, performed without physiologic pressure, have shown that quantitative histologic values for lumen area and wall thickness were consistently smaller ( $10 \%$ to $41 \%$ ) than the corresponding intravascular ultrasound values. $5,8,12,25,27$ Similar observations were reported by Potkin et al. ${ }^{7}$ : histologic values for vessel area and 

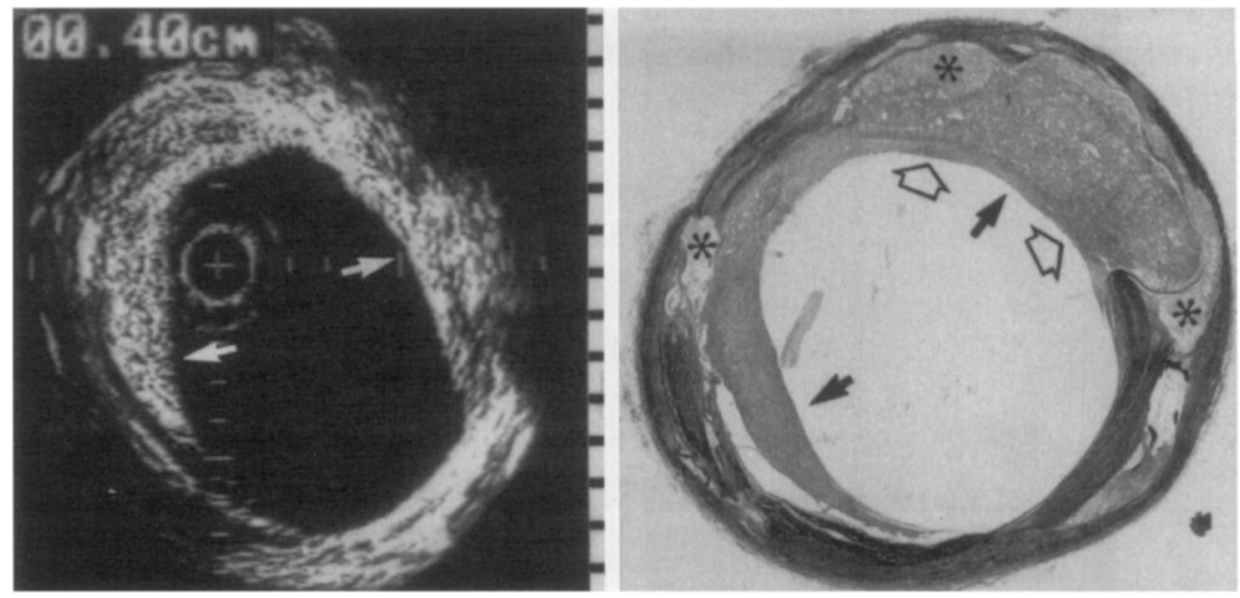

Fig. 3. Intravascular ultrasound cross-section (left) and corresponding histologic section (right) obtained from iliac artery show characteristics of previous plaque rupture. On ultrasound, soft lesion is apparent (solid arrows); arterial media is invisible because of extensive atherosclerosis. On histologic examination, lesion represents thrombus (solid arrows) and focal lipid deposits with cholesterol crystals (asterisk). Open arrow, Torn ends of fibrous cap. Lipid did not appear as hypoechoic region on ultrasound, probably because of large content of cholesterol crystals. Calibration: $1 \mathrm{~mm}$.

wall thickness were smaller (10\% and $19 \%$, respectively) than their echographic counterparts. In contrast, they reported that histologic values for lumen area were larger (18\%) than the corresponding echographic values. ${ }^{7}$ However, Nishimura et al. ${ }^{24}$ performed pressurized in vitro studies and reported no difference between lumen area measured with intravascular ultrasound and that measured histologically. We assume that the underlying mechanism of the reduction evidenced histologically is tissue shrinkage resulting from histologic processing. ${ }^{5,8,25}$ The reasons for the reported variability in the in vitro measurements may include selection of the specimens studied and procedural differences.

\section{IN VITRO OBSERVATIONS AFTER INTERVENTION}

In vitro imaging of atherosclerotic vessels before and after intervention enables assessment of the response of the atherosclerotic lesion and the vessel wall to the intervention.

Tobis et al. ${ }^{25}$ were the first to analyze corresponding ultrasound images $(20 \mathrm{MHz})$ obtained before and after balloon angioplasty to assess the qualitative and quantitative effects of the procedure. They established that the mean cross-sectional lumen area increased from 8.7 to $15.1 \mathrm{~mm}^{2}$ after dilatation; plaque disruption and dissection were readily visible. We observed that with the use of $30 \mathrm{MHz}$ ultrasound transducers, in addition to dissection and plaque rupture, media rupture can be visualized both in coronary and in peripheral arteries ${ }^{30,} 31$ (Fig. 2 ). Visualization of media rupture seems to depend on the ultrasound frequency used and is strongly related to the presence of a dissection.

The sensitivity of ultrasound for revealing vascular damage (including dissection and plaque rupture) in vitro after balloon angioplasty was high $(81 \%$ and $83 \%$, respectively) in coronary and peripheral arteries. ${ }^{20,25,32}$ However, detection of dissection with intravascular ultrasound was achieved more frequently in peripheral arteries than in coronary arteries: the stenting effect of the ultrasound catheter may prevent visualization of dissection in the latter. ${ }^{33}$

From ongoing in vitro studies that systematically examined coronary arteries before and after balloon angioplasty we learned that the increase in lumen area seen after intervention was caused by an increase in media-bounded area (85\%) and a slight reduction (15\%) in plaque area. Moreover, these studies showed that the quantitative changes seen at the most stenotic site after intervention were greater than those obtained from a sequence of corresponding cross-sections within the dilated specimen. ${ }^{31}$ Differences encountered for the increase in lumen area were $60 \%$ versus $30 \%$, for the increase in media-bounded area $20 \%$ versus $12 \%$, and for the reduction in plaque area $8 \%$ versus $5 \%$.

\section{INTRAVASCULAR ULTRASOUND AND VEINS}

In vitro intravascular ultrasound studies on veins and saphenous veins used for bypass grafting are limited. It has been found that these vessels do not show a characteristic hypoechoic media. ${ }^{4,34,35}$ The 

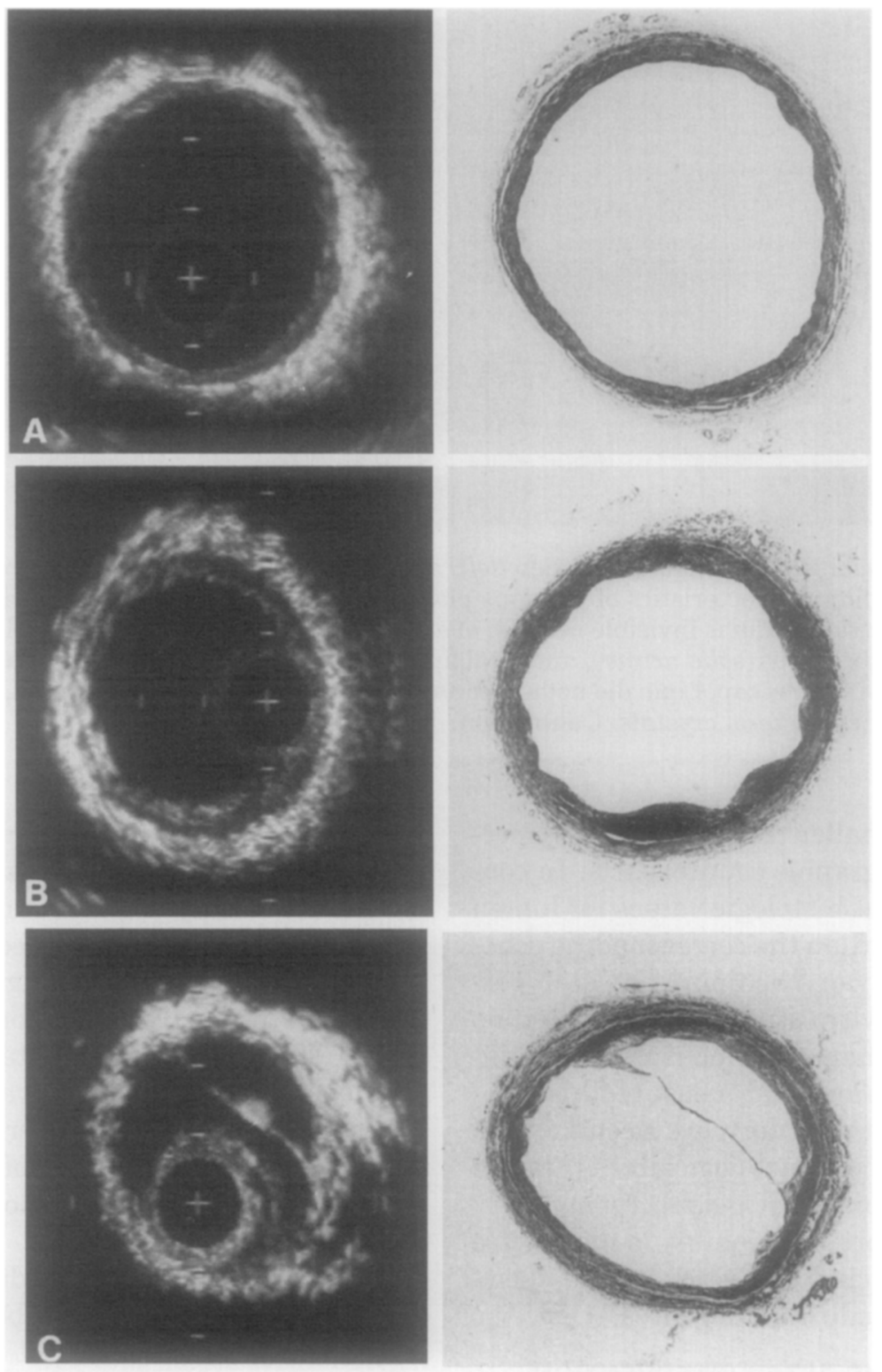

Fig. 4. Intravascular ultrasound cross-sections (left) and corresponding histologic sections (right) show normal vein wall (A) appearing echographically as two-layered structure, slightly thickened vein wall (B) appearing as homogeneous structure within outer hyperechoic layer, and vein leaflet (C) appearing as a bright structure. Calibration: $1 \mathrm{~mm}$.

media of a saphenous vein consists of circularly, or circularly and longitudinally disposed, smooth-muscle cells and collagen and few elastin fibers.

Initially a normal vein was recognized as a nonlayered homogeneous vessel wall on ultrasound. , $^{44}$ Willard et al. ${ }^{34}$ established a good correlation between ultrasound imaging (20 MHz) and histologic analyses, with the ability to distinguish among normal intima, intimal hyperplasia, vein wall fibrosis, and atheromatous plaque. Wall thickness was significantly greater in the vein grafts after long-term implantation than in the freshly harvested veins (mean thickness $1.4 \pm 0.5 \mathrm{~mm}$ vs $0.7 \pm 0.2 \mathrm{~mm}$, respectively); this finding correlated histologically with vein wall fibrosis.

Similar observations were made by van der Lugt et al. ${ }^{35}$ The ultrasound images $(30 \mathrm{MHz})$ portrayed the vein wall as a two-layered structure that consists of a hypoechoic inner layer representing the tunica intima and media and a hyperechoic outer layer representing the adventitia (Fig. 4). ${ }^{35}$ The median thickness of an apparently normal vein wall mea- 

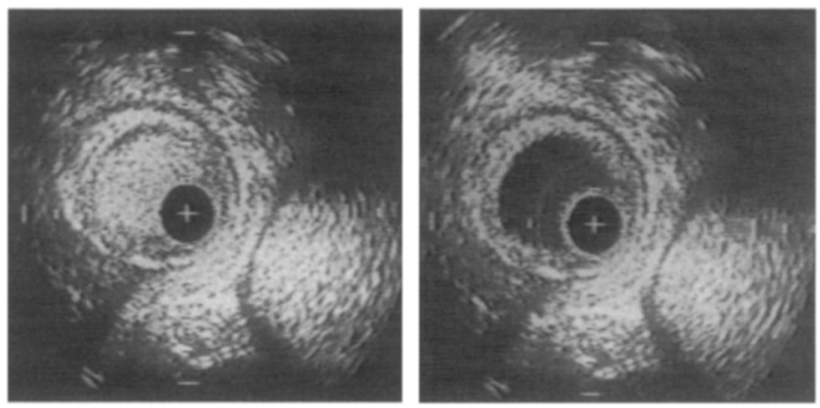

Fig. 5. Intravascular ultrasound cross-sections obtained in vivo show echogenicity of stagnated blood, which causes difficulty in discrimination of luminal boundary on stillframe (left). Saline flush eliminates presence of blood (right). At 4 o'clock position, vein is seen. Calibration: 1 $\mathrm{mm}$.

sured on ultrasound was $0.3 \mathrm{~mm}$ (range 0.1 to 0.5 $\mathrm{mm}$ ). Thickening of the vein wall was visible as a homogeneous structure within the outer hyperechoic layer (Fig. 4). In the absence of calcification, no clear difference in ultrasound appearance was found between the arterialized vein wall and the vein wall with preexisting thickening. ${ }^{4}$ The presence of leaflets in the venous segments was readily seen on intravascular ultrasound: they appear as echogenic lines within the lumen (Fig. 4).

\section{DIFFERENCES BETWEEN IN VITRO AND IN VIVO SETTINGS}

Although in vitro studies are necessary to understand the images acquired in patients, several differences between in vitro and in vivo use of intravascular ultrasound should be taken into account. One important difference in coronary imaging is the presence of a beating heart; other differences include the influence of blood and blood pressure.

Influence of blood. Because the velocity of sound in saline differs from that in blood, intravascular ultrasound studies performed in an in vitro setting with saline solution result in higher quantitative values than in vivo studies in which blood is the medium. $^{36,37}$ For this reason, the ultrasound system should be properly calibrated to allow correct measurements during clinical use.

In clinical studies the scatter intensity of flowing blood may facilitate recognition of vascular damage, such as dissection and media rupture, on real-time images by serving as a contrasting acoustic interface. ${ }^{37}$ In still frames, however, quantitative analysis of the ultrasound image may be hampered because the intensity of blood scatter may be similar in magnitude to vessel-wall scatter, thus causing diffi-

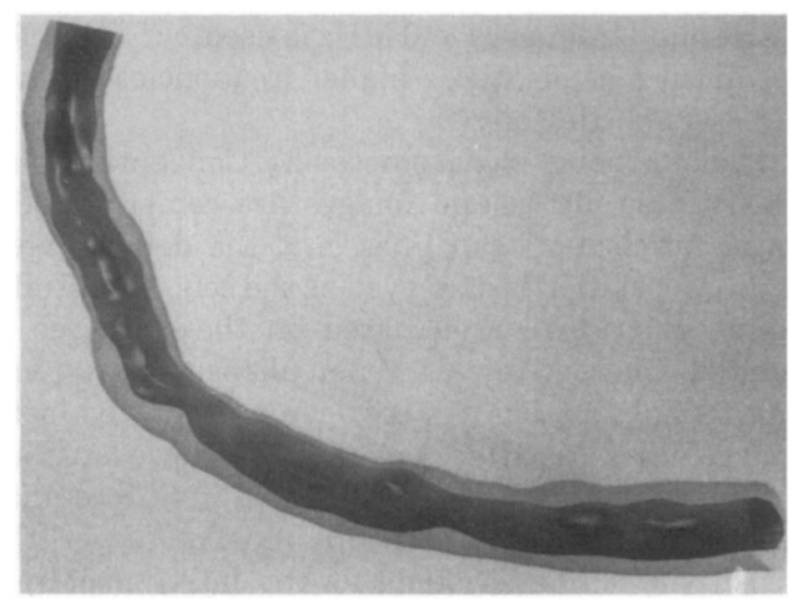

Fig. 6. Example of rendered ANGUS reconstruction of right coronary artery as observed in frontal projection. To enhance 3D aspects, some arbitrarily chosen highlights are added on surface of solid wall of lumen. Arterial wall is shown as transparent material. (From Slager et al. Thoraxcenter J 1995;7:(3)36-7.)

culty in discrimination of the luminal boundary (Fig. 5). Temporal averaging of the images to some extent solves this problem but introduces smearing of the vessel wall. ${ }^{37}$ Similarly, difficulties in interpretation may occur when the echogenicity of stagnant blood increases (Fig. 5). In these instances, saline flush should be applied to eliminate the echogenic blood. $^{30,37}$

Influence of blood pressure. Although initial intravascular ultrasound studies in vitro were not commonly performed under physiologic pressure, no noticeable differences in vessel wall and plaque morphologic features are expected to be found. Physiologic pressure may result in an increase in lumen area and in a thinning of the three-layered arterial wall. ${ }^{11,12,38}$

\section{FUTURE IN VITRO RESEARCH}

Future in vitro research with intravascular ultrasound should aim to increase the diagnostic differentiation of plaque morphologic characteristics and to facilitate on-line quantitative assessment of vessel geometric structure. These goals may be achieved by the following modalities: higher ultrasound frequency, radiofrequency signal processing, contour detection, three-dimensional (3D) imaging, and elastography.

Higher ultrasound frequency. Use of a higher ultrasound frequency offers better axial and lateral resolution and consequently more diagnostic information on morphologic features, particularly in small coronary arteries. Image quality improves when an 
ultrasound frequency $>40 \mathrm{MHz}$ is used, ${ }^{3,11,39}$ but for technical reasons, these higher frequencies are not yet applied clinically.

Radiofrequency signal processing. Conventional intravascular ultrasound images are composed of a great number of scan lines, and the demodulated echo information is displayed as the echo amplitude; tissue characterization based on these images is limited. Current intravascular ultrasound systems can reliably distinguish between noncalcified (soft) and calcified (hard) lesions (Fig. 2). However, they are unable to distinguish soft lesion in fibrocellular lesion, fibrous lesion, and thrombus; moreover, the sensitivity of these systems for the detection of lipid is low. ${ }^{18,}{ }^{19}$ Clinically, there is a need for improved delineation of the lesion composition. The introduction of radiofrequency signal processing in intravascular ultrasound imaging may enable better tissue characterization. ${ }^{40-42}$ In addition to the demodulated echo amplitude, radiofrequency signal processing provides spectral and phase information. The results obtained from in vitro studies suggest that these parameters may be effective for tissue characterization. ${ }^{41,42}$

Contour detection. Quantitative analysis of clinical intravascular ultrasound data is a time-consuming off-line technique. So far, on-line analysis is based on semiquantitative assessment. On-line quantitative analysis using automatic contour detection based on echo amplitude information is seriously hampered by the intensity of blood - scatter in vivo, which may have a magnitude similar to vessel-wall scatter (Fig. 5). On the basis of the correlation of radiofrequency traces, a better discrimination between blood and vessel wall can be achieved. ${ }^{43}$ This technique can markedly enhance the accuracy of the quantitative data and will enable direct reintervention based on reliable quantitative intravascular ultrasound data.

3D imaging. In vitro validation is mandatory for 3D intravascular ultrasound. Two-dimensional images are acquired at varying depth with use of a pull-back device and afterward reconstructed in 3D. Conventional $3 \mathrm{D}$ visualization of vessels is already possible in intravascular ultrasound and provides additional geometric information. ${ }^{44}$ The combination of biplane angiography with 3D ultrasound imaging (ANGUS) may overcome the limitation of "conventional" $3 \mathrm{D}$ reconstruction, which images each vessel as an almost straight tube. ${ }^{45}$ Application of the ANGUS technique may improve 3D quantitative studies of changes in the geometric characteristics of the vessel wall and lumen after intervention (Fig. 6). Furthermore, these geometric changes may be studied quantitatively in relation to blood flow-derived pa- rameters, such as shear stress, on the basis of the principles of fluid dynamics. Another field of interest is the assessment of tissue characterization over a $3 \mathrm{D}$ volume. ${ }^{42}$ Skill in on-line bedside $3 \mathrm{D}$ visualization of lipid pools is a clinical challenge, and the procedure needs to be validated in in vitro experiments.

Elastography. Elastography is an important future application of radiofrequency signal processing to intravascular ultrasound. This technique applies a (quasi)static or dynamic stress to the tissue and then measures the strain by means of the phase information obtained from the radiofrequency signals. ${ }^{40,46-48}$ From this information, the local elasticity of tissue can be determined. Knowledge of the local elasticity is important for tissue characterization and for stent design. However, this technique must first be developed in vitro, and extensive study will be needed before clinical application.

\section{CONCLUSION}

Information gleaned from in vitro ultrasound studies is indispensable for the understanding of observations made in vivo. Furthermore, it establishes which of the qualitative and quantitative intravascular ultrasound parameters are reliable and reproducible and thus may be used for clinical application. The challenge for the future is to establish whether ongoing in vitro research aimed at tissue identification, on-line bedside automatic quantitative assessment, and $3 \mathrm{D}$ reconstruction will increase the beneficial role of intravascular ultrasound for decision-making during intervention.

\section{SUMMARY}

In vitro studies have established that intravascular ultrasound is a reliable technique for accurate assessment of vascular anatomic structure and disease conditions before and after intervention. In addition, quantitative data from intravascular ultrasound studies correspond well with histologic findings, which serve as the gold standard. These in vitro studies permit the understanding and interpretation of ultrasound images obtained in vivo, although differences between the two settings should be taken into account. New ultrasound modalities currently being developed may enhance the diagnostic differentiation of plaque morphologic characteristics and facilitate on-line quantitative assessment of vessel structure.

\section{REFERENCES}

1. Meyer CR, Chiang EH, Fechner KP, Fitting DW, Williams DM, Buda AJ. Feasibility of high-resolution intravascular ultrasonic imaging catheters. Radiology 1988;168:113-6. 
2. Pandian NG, Kreis A, Brockway B, Isner JM, Sacharoff A, Boleza E, et al. Ultrasound angioscopy: real-time, two-dimensional, intraluminal ultrasound imaging of blood vessels. Am J Cardiol 1988;62:493-4.

3. Gussenhoven EJ, Essed CE, Frietman P, van Egmond F, Lancée CT, van Kappellen WH, et al. Intravascular ultrasonic imaging: histologic and echographic correlation. Eur J Vase Surg 1989;3:571-6.

4. Gussenhoven WJ, Essed CE, Frietman P, Mastik F, Lancée C, Slager C, et al. Intravascular echographic assessment of vessel wall characteristics: a correlation with histology. Int J Cardiac Imaging 1989;4:10516.

5. 5. Gussenhoven EJ, Essed CE, Lancée CT, Mastik F, Frietman P, van Egmond FC, et al. Arterial wall characteristics determined by intravascular ultrasound imaging: an in vitro study. J Am Coll Cardiol 1989; 14:947-52.

6. Yock PG, Linker DT, Angelsen BAJ. Two-dimensional intravascular ultrasound: technical development and initial clinical experience. J Am Soc Echocardiogr 1989;2:296-304.

7. Potkin BN, Bartorelli AL, Gessert JM, Neville RF, Almagor Y, Roberts WC, et al. Coronary artery imaging with intravascular high-frequency ultrasound. Circulation 1990;81:1575-85.

8. Mallery JA, Tobis JM, Griffith J, Gessert J, McRae M, Moussabeck O, et al. Assessment of normal and atherosclerotic arterial wall thickness with an intravascular ultrasound imaging catheter. Am Heart J 1990; 119:1392-400.

9. Bartorelli AL, Neville RF, Keren G, Potkin BN, Almagor Y, Bonner RF, et al. In vitro and in vivo intravascular ultrasound imaging. Eur Heart J 1992;13:102-8.

10. Kerber S, Fechtrup C, Budde T, Fahrenkamp A, Böcker W, Breithardt G. Validation of intravascular altrasound in arteriosclerotic peripheral vessels. Int J Cardiol 1994;43:191-8.

11. Lockwood GR, Ryan LK, Gotlieb AI, Lonn E, Hunt JW, Liu P, et al. In vitro high resolution intravascular imaging in muscular and elastic arteries. J Am Coll Cardiol 1992;20:153-60.

12. Gussenhoven EJ, Frietman PAV, The SHK, van Suylen RJ, van Egmond FC, Lancée CT, et al. Assessment of medial thinning in atherosclerosis by intravascular ultrasound. Am J Cardiol 1991;68:162532.

13. Porter TR, Radio SJ, Anderson JA, Michels A, Xie F. Composition of coronary atherosclerotic plaque in the intima and media affects intravascular ultrasound measurements of intimal thickness. J Am Coll Cardiol 1994;23:1079-84

14. Di Mario C, The SHK, Madretsma S, van Suylen RJ, Wilson RA, Bom $N$, et al. Detection and characterization of vascular lesions by intravascular ultrasound: an in-vitro correlative study with histology. J Am Soc Echocardiogr 1992;5:135-46.

15. Borst C, Savalle LH, Smits PC, Post MJ, Gussenhoven WJ, Bom N. Imaging of post-mortem coronary arteries by $30 \mathrm{MHz}$ intravascular ultrasound. Int J Cardiac Imaging 1991;6:239-46.

16. Fitzgerald PJ, St. Goar FG, Connoly AJ, Pinto FJ, Billingham ME, Popp RL, et al. Intravascular ultrasound imaging of coronary arteries: is three layers the norm? Circulation 1992;86:154-8.

17. Gussenhoven EJ, van der Lugt A, The SHK, de Feyter P, Serruys PW, van Suylen RJ, et al. Similarities and differences between coronary and iliofemoral arteries related to intravascular ultrasound. In: Roelandt et al., Gussenhoven EJ, Bom N. eds. Intravascular ultrasound. Dordrecht: Kluwer Academic, 1993:45-62.

18. Sechtem U, Arnold G, Keweloh T, Casper C, Curtius JM. In-Vitro-Diagnose der koronaren Plaquemorphologie mit Intravasculärem Ultraschall: Vergleich mit Histopatologischen Befunden. Zeitschr Kardiol 1993;82:618-27.

19. Peters RJG, Kok WEM, Havenith MG, Rijsterborgh H, van der Wal AC, Visser CA. Histopathologic validation of intracoronary ultrasound imaging. J Am Soc Echocardiogr 1994;7:230-41.

20. Siegel RJ, Ariani M, Fishbein MC, Chae JS, Park JC, Maurer GM, et al. Histopathologic validation of angioscopy and intravascular ultrasound. Circulation. 1991;84:109-17.

21. Pandian NG, Kreis A, Brockway B. Detection of intravascular thrombus by intravascular high frequency two-dimensional ultrasound imaging in vitro and in vivo studies. Am J Cardiol 1990;65: 1280-3.

22. Frimerman A, Miller HI, Hallman M, Laniado S, Keren G. Intravas- cular ultrasound characterization of thrombi of different composition. Am J Cardiol 1994;73:1053-7.

23. Di Mario C, Madretsma S, Linker D, The SHK, Bom N, Serruys PW, et al. The angle of incidence of the ultrasonic beam: a critical factor for the image quality in intravascular ultrasonography. Am Heart J 1993; 125:442-8.

24. Nishimura RA, Edwards WD, Warnes CA, Reeder GS, Holmes DR, Tajik AJ, et al. Intravascular ultrasound imaging: in vitro validation and pathologic correlation. J Am Coll Cardiol 1990;16:145-54.

25. Tobis JM, Mallery JA, Gessert J, Griffith J, Mahon D, Bessen M, et al. Intravascular ultrasound cross sectional arterial imaging before and after balloon angioplasty in vitro. Circulation 1989;80:873-82.

26. Tabbara M, Kopchok G, White RA. In vitro and in vivo evaluation of intraluminal ultrasound in normal and atherosclerotic arteries. Am J Surg 1990;160:556-60.

27. Pandian NG, Weintraub A, Kreis A, Schwartz SL, Konstam MA, Salem DN. Intracardiac, intravascular, two-dimensional, high-frequency ultrasound imaging of pulmonary artery and its branches in humans and animals. Circulation 1990;81:2007-12.

28. Yoshida K, Yoshikawa J, Akasaka T, Yamaura Y, Shakudo M, Takagi $\mathrm{T}$, et al. Intravascular ultrasound imaging: in vitro and vivo validation. Jpn Circ J 1992;56:572-7.

29. Wenguang L, Gussenhoven WJ, Zhong Y, The SHK, Di Mario C, Madretsma S, et al. Validation of quantitative analysis of intravascular ultrasound images. Int J Cardiac Imaging 1991;6:247-53.

30. The SHK, Gussenhoven EJ, Zhong Y, Li W, van Egmond F, Pieterman $\mathrm{H}$, et al. Effect of balloon angioplasty on the femoral artery evaluated with intravascular ultrasound imaging. Circulation 1992;86:48393.

31. van der Lugt A, Gussenhoven EJ, Stijnen T, van Strijen M, van Driel E, van Egmond FC, van Suylen RJ, et al. Comparison of intravascular ultrasonic findings after coronary balloon angioplasty evaluated in vitro with histology. Am J Cardiol 1995;76:661-6.

32. Coy KM, Park JC, Fishbein MC, Laas T, Diamond GA, Adler L, et al. In vitro validation of three-dimensional intravascular ultrasound for the evaluation of arterial injury after balloon angioplasty. J Am Coll Cardiol 1992;20:692-700.

33. Fitzgerald PJ, Ports TA, Yock PG. Contribution of localized calcium deposits to dissection after angioplasty: an observational study using intravascular ultrasound. Circulation 1992;86:64-70.

34. Willard JE, Netto D, Demian SE, Haagen DR, Brickner ME, Eichhorn $\mathrm{EJ}$, et al. Intravascular ultrasound imaging of saphenous vein grafts in vitro: comparison with histologic and quantitative angiographic findings. J Am Coll Cardiol 1992;19:759-64.

35. van der Lugt A, Gussenhoven EJ, van Essen J, van Urk H. Venous bypass imaging with intravascular ultrasound. In: Greenhalgh $\mathrm{R}$, ed. Vascular imaging for surgeons. London: WB Saunders, 1995:36175 .

36. Chae JS, Brisken AF, Maurer G, Siegel RJ. Geometric accuracy of intravascular ultrasound imaging. J Am Soc Echocardiogr 1992;5:57787.

37. Li W, Gussenhoven EJ, Zhong Y, The SHK, Pieterman H, van Urk H, et al. Temporal averaging for quantification of lumen dimensions in intravascular ultrasound images. UTtrasound Med Biol 1994;20:11722.

38. Siegel RJ, Chae JS, Maurer G, Berlin M, Fishbein MC. Histopathologic correlation of the three-layered intravascular ultrasound appearance of normal adult human muscular arteries. Am Heart J 1993;126: $872-8$.

39. Lockwood GR, Ryan LK, Hunt JW, Foster FS. Measurement of the ultrasonic properties of vascular tissues and blood from $35-65 \mathrm{MHz}$. U1trasound Med Biol 1991;17:653-66.

40. Bom N, Li W, van der Steen AFW, de Korte CL, Gussenhovem EJ, von Birgelen C, et al. Intravascular Ultrasound: technical update. In: de Feyter PJ, Di Mario C, Serruys PW, eds. Quantitative coronary imaging. Rotterdam: Barjesteh, Meeuwes and Co., 1995:8906.

41. Wickline SA, Miller JG, Rechia D, Sharkey AM, Bridal L, Christy D. Beyond intravascular imaging: quantitative ultrasonic tissue characterization of vascular pathology. IEEE Ultrasonics Symposium 1994; 3:1589-97. 
42. Wilson LS, Neale ML, Talhami HE, Appleberg M. Preliminary results from attenuation-slope mapping of plaque using intravascular ultrasound. Ultrasound Med Biol 1994;20:529-42.

43. Li W, van der Steen AFW, Honkoop J, Gussenhoven EJ, Lancée CT, Bom $\mathrm{N}$. Temporal correlation of blood scattering signals on radiofrequency intravascular ultrasound in vivo. Ultrasound Med Biol 1996 [In press].

44. Rosenfield K, Losordo DW, Ramaswamy K, Pastore JO, Langevin RE, Razvi S, et al. Three-dimensional reconstruction of human coronary and peripheral arteries from images recorded during two-dimensional intravascular ultrasound examination. Circulation 1991;84:1938-56.

45. Slager CJ, Laban M, Oomen JAF, von Birgelen C, Wenguang L, Krams
$\mathrm{R}$, et al. Three-dimensional geometry and orientation of coronary lumen and plaque: Reconstruction from angiography and ICUS (ANGUS). Thoraxcenter J 1995;7(3):36-7.

46. Cespedes I, Ophir J, Ponnekanti H, Maklad N. Elastography: elasticity imaging using ultrasound with application to muscle and breast in vivo. Ultrasonic Imaging 1993:15:73-88.

47. Talhami HE, Wilson LS, Neale ML. Spectral tissue strain: a new technique for imaging tissue strain using intravascular ultrasound. Ultrasound Med Biol 1994;20:759-72.

48. Lerner RM, Huang SR, Parker KJ. 'Sonoelasticity' images derived from ultrasound signals in mechanically vibrated tissues. Ultrasound Med Biol 1990;16:231-9. 